\title{
Input-output data and service outsourcing. A reply to Dietrich, McCarthy and Anagnostou
}

\author{
Giuseppe Vittucci Marzetti*
}

\begin{abstract}
In a recent paper, McCarthy and Anagnostou (2004, The impact of outsourcing on the transaction costs and boundaries of manufacturing, International Journal of Production Economics, 88, pp. 61-71) use a decomposition approach put forward by Dietrich (1999, Explaining economic restructuring: an input-output analysis of organisational change in the European Union, International Review of Applied Economics, 13(2), pp. 219-40) to analyze the impact of contracting-out in the UK manufacturing decline over the '80s and the '90s.

Dietrich claims that this decomposition can distinguish the part of the manufacturing output decrease produced by the increased integration of services in manufacturing from the one which is instead produced by final demand-related changes.

This paper aims at critically examining Dietrich's decomposition approach and showing its flaws. In so doing, the paper also carefully analyzes the changes outsourcing produces in input-output tables. Thus, it might prove useful also in avoiding further mistakes in using input-output analysis for studying outsourcing-related changes in economic structure.
\end{abstract}

Keywords Outsourcing; Input-output methodology; Dietrich's decomposition; Manufacturing.

JEL Classification: E010; D570; L240; L600; O140.

*Address: Department of Economics, University of Bologna, Strada Maggiore 45, 40125 Bologna, Tel.: +39 051 2092651, Fax.: +39 051 237002, Email: gvittucci@yahoo.it 


\section{Introduction}

Recent years have seen a widespread diffusion of outsourcing practices in more developed countries. Firms have usually resorted to contracting-out in order to refocus on core competences and increase efficiency. ${ }^{1}$ This has entailed transformations in the actual organization of production, deeply affecting sectoral boundaries. Indeed, by reducing the level of vertical integration of firms, outsourcing can in fact increase horizontal linkages among sectors, thus contributing to create intersectoral networks of productive relations. In particular, the spread of service outsourcing practices among manufacturing firms has determined a considerable increase in the actual integration of business services in manufacturing.

Growing evidence on the important role played by such effects, those associated with the transformation of the boundaries between manufacturing and services entailed by service outsourcing in particular, has recently spurred some economists to abandon the micro perspective within which outsourcing is usually studied and analyze outsourcing-related structural changes.

Within this strand, Dietrich (1999) put forward a method based on inputoutput relations for disentangling the role of organizational changes in sectoral gross production variations. This method, he claims, can distinguish the part of the manufacturing output decrease produced by the increased integration of services in manufacturing ("supply-side restructuring") from the one which is instead produced by final demand-related changes.

Using this method, McCarthy \& Anagnostou (2004) have recently tried to analyze the impact of service outsourcing in the decline occurred in the UK manufacturing from the late ' 80 s to the middle '90s.

However, it can be proved that Dietrich's decomposition has got some important flaws. In the present paper, I will discuss at some length the way in which input-output tables actually collect economic phenomena in order to show that the decomposition does not measure what they claim it does.

The work is organized as follows. In Sections 2 and 3, I will briefly review the decomposition method put forward by Dietrich (1999) and the analysis accomplished by McCarthy \& Anagnostou (2004). In Section 4, I will discuss the "input-output manifestations" of contracting-out. Then, in Section 5, I will critically reexamine Dietrich's method, showing its flaws. Section 6 concludes the paper summing up the main results.

\footnotetext{
${ }^{1}$ At the risk of being somehow inaccurate, in what follows I will use contracting-out and outsourcing as synonyms.
} 


\section{Dietrich's decomposition approach}

Using basic input-output relations, Dietrich decomposes the changes in the sectoral gross production vector $(\mathbf{q})$ as follows:

$$
\begin{aligned}
\Delta \mathbf{q}_{t}=\mathbf{q}_{t}-\mathbf{q}_{t-1}=\mathbf{L}_{t} \mathbf{y}_{t}-\mathbf{L}_{t-1} \mathbf{y}_{t-1} & =\mathbf{L}_{t-1} \Delta \mathbf{y}_{t}+\Delta \mathbf{L}_{t} \mathbf{y}_{t} \\
& =\mathbf{L}_{t} \Delta \mathbf{y}_{t}+\Delta \mathbf{L}_{t} \mathbf{y}_{t-1}
\end{aligned}
$$

where $\mathbf{L}_{t}$ and $\mathbf{y}_{t}$ stand for, respectively, the Leontief inverse matrix and the final demand vector of period $t$.

Arguing that "there is no a priori reason for weighting supply (demand) changes using first or second period demand (supply)" (1999, p.223), Dietrich takes arithmetic average of Equations (1) and (2) and writes the changes in the gross output as follows:

$$
\Delta \mathbf{q}_{t}=\underbrace{\left(\frac{\mathbf{L}_{t-1}+\mathbf{L}_{t}}{2}\right) \Delta \mathbf{y}_{t}}_{Q D}+\underbrace{\Delta \mathbf{L}_{t}\left(\frac{\mathbf{y}_{t-1}+\mathbf{y}_{t}}{2}\right)}_{Q S}
$$

The first term in the right hand side of Equation (3) ( $Q D$ ) works out, for each sector in the economy, "the average demand induced change in output", while the second term $(Q S)$ "defines the average supply led change in output", i.e. it "captures that part of the change in gross output attributable to the change in the technical coefficients" (Dietrich, 1999, p.223).

Dietrich claims that, keeping final demand and technology constant, service outsourcing made by manufacturing firms brings forth a decrease in the manufacturing output and a correspondent increase in the production of services and it is therefore associated with negative values of $Q S$ in manufacturing. This is because for Dietrich "each element in a use matrix identifies a production process including intermediate activities for in-house use which are, by definition, not outputs sold to other users and not bought from other suppliers" (Dietrich, 1999, pp.223-224).

In order to have a closer look at Dietrich's argument, I will follow his simple example of a fictitious two-industry economy (manufacturing-services), whose basic input-output relations are:

$$
\left(\begin{array}{c}
q_{m} \\
q_{s}
\end{array}\right)=\left(\begin{array}{lll}
w_{m m} & + & w_{m s} \\
w_{s m} & + & w_{s s}
\end{array}\right)+\left(\begin{array}{c}
y_{m} \\
y_{s}
\end{array}\right)
$$

where $q_{i}, y_{i}$ and $w_{i j}(i, j=m, s)$ denote, respectively, the gross production of industry $i$, the output from industry $i$ supplying the final demand, and the intermediate flows from industry $i$ to $j$. 
According to Dietrich, keeping final demand constant, there will be a reduction in $w_{m m}$ and a correspondent increase in $w_{s m}$ every time, in manufacturing, firms sub-contracting service activities to firms classified in services grow at the expense of the remaining manufacturing firms, producing service activities in-house for their own use. Thus, "with given final demands $[\ldots]$ and because of the general I-O accounting framework, this inter-industry change because of firm-based restructuring will imply an equivalent reduction in $q_{m}$ and increase in $q_{s} "$ (Dietrich, 1999, pp.225).

In order to get rid of inflation, rendering comparison over time somewhat difficult, rather than comparing absolute values using constant prices, Dietrich calculates the manufacturing gross output and the sectoral final demand as a proportion of the total output and decomposes the changes in the "proportion of gross output that an industry accounts for" (Dietrich, 1999, p.226). This is because, on the one hand, there is a lack of reliable data at constant prices; on the other hand, as he argues, using data at constant prices inevitably "shifts consideration away from control over value production to allocation of physical outputs", thus removing a major explanation of supply side change from the data, that is, "the net ability of different agents to charge higher prices and hence extract greater returns for any good/service provided, given productivity growth and supply-demand shifts", which is the main determinant of differential inflation rates at a micro level (Dietrich, 1999, p.226).

Accordingly, Equation (3) changes as follows: ${ }^{2}$

$$
\Delta\left(\frac{\mathbf{q}}{Q}\right)_{t}=\frac{\mathbf{q}_{t}}{Q_{t}}-\frac{\mathbf{q}_{t-1}}{Q_{t-1}}=\underbrace{\left(\frac{\mathbf{L}_{t-1}+\mathbf{L}_{t}}{2}\right) \Delta\left(\frac{\mathbf{y}}{Q}\right)_{t}}_{Q D^{*}}+\underbrace{\Delta \mathbf{L}_{t} \frac{1}{2}\left(\frac{\mathbf{y}_{t-1}}{Q_{t-1}}+\frac{\mathbf{y}_{t}}{Q_{t}}\right)}_{Q S^{*}}
$$

where $Q_{t}$ is the total gross output in period $t$.

\section{McCarthy and Anagnastou's input-output study}

In a recent paper, after a brief review of benefits and costs economic literature has often attached to outsourcing, McCarthy \& Anagnostou (2004) point out how outsourcing has changed firm boundaries in manufacturing by encouraging "manufacturing organizations to [...] become extended enterprises by setting up partnerships, and by collaborating and trading with other manufacturing, service and transportation organizations." This has progressively

\footnotetext{
${ }^{2}$ This equation is not explicitly stated in Dietrich's paper.
} 
resulted in "a nebulous manufacturing sector, with indistinct manufacturing organizations creating wealth through the governance of knowledge and physical production activities. The result is that the conventional boundaries of manufacturing value are not appropriate" (McCarthy \& Anagnostou, 2004, p.65).

Given the increased integration between manufacturing and services the UK economic restructuring has produced, the manufacturing decline this country has experienced since the ' 80 s might have been somehow overstated by standard sectoral analysis. Therefore, they decide to resort to Dietrich's method for estimating such bias.

They apply Dietrich's decomposition to UK annual input-output tables at constant prices from 1989 to 1998 and work out, for each year, $Q D$ and $Q S$ values for manufacturing (see Equation (3)). Then, they subtract $Q S$ to the manufacturing gross output of the correspondent year to compute the manufacturing output that would have been if no shrink due to changes in technical coefficients had occurred. ${ }^{3}$

Then, using the latter values together with yearly measures of the total gross output $\left(Q_{t}\right)$, for each year they calculate the manufacturing share that would have been in the non-outsourcing case and compare it with the actual share of manufacturing, to finally assess to what extent sectoral data overestimate manufacturing decline. ${ }^{4}$

\section{Input-output data and service outsourcing}

In dealing with outsourcing, it has to be firstly stressed that in the literature it is defined with respect to firms, while the elementary statistical unit in national accounts is the establishment. In SNA93 an establishment is defined as "an enterprise, or part of an enterprise, that is situated in a single location and in which only a single (non-ancillary) productive activity is carried out or in which the principal productive activity accounts for most of the value added" (United Nations, 2006, par.5.21, emphasis mine).

For what may concern contracting-out, this has two major implications. On the one side, intra-establishment deliveries, that is, deliveries of goods and

\footnotetext{
${ }^{3}$ Just to give an example, being the estimated $Q S$ between 1997 and 1998 equal to -9, 229 (£ million), they subtract this value to the manufacturing output of $1997(378,851)$ to obtain the value that would have been if no such effect had occurred $(388,080)$ (McCarthy \& Anagnostou, 2004, p.69).

${ }^{4}$ For example, using the value of the total gross output in $1997(1,526,371)$, they calculate the manufacturing share in the non-outsourcing case $(388,080 / 1,526,371 \times 100=$ $2.54)$ and compare it with the real one $(378,851 / 1,526,371 \times 100=2.48)$ (McCarthy \& Anagnostou, 2004, p.69).
} 
services produced and consumed within the same accounting period within the same establishment, are not counted as products, thus included neither in intermediate consumption nor in output. On the other side, each sector results from an establishment-based aggregation, while firms as such are not directly taken into account. In particular, in input-output tables the term industry refers to "the kind of activity into which all units which engage primarily in that kind of activity are aggregated" (United Nations, 1999, p.42). Given that the statistical unit is the establishment, each industry comes from the aggregation of establishments engaged exclusively or primarily in a certain kind of activity, no matter the firm they belong to. ${ }^{5}$

The above remarks have deep consequences for Dietrich's approach. In order to fully grasp them, let us recall the simple example made by Dietrich of a two-industry economy (see Equation (4)).

With respect to the provision of an intermediate service in a manufacturing firm, the possible cases are four:

(1) the firm has got an establishment whose primary activity is the provision of such service;

(2) the task is accomplished by an establishment of the firm, but this provision is the secondary activity of the establishment itself;

(3) the service is provided within each establishment and there is no external transaction of such service among different establishments either within or outside the boundaries of the firm;

(4) the firm acquires the bundle of services from an external service provider.

It is crucial to assess where the economic activities producing such service are recorded in the previous transaction matrix of Equation (4) in each of the cases outlined above.

In case 1 and 4 they are included in $w_{s m}$, while in case 2 , if the main activity of the establishment is the production of manufactured goods, they are recorded in $w_{m m}$. On the contrary, in case 3 they are simply not recorded: the activities producing such service entail intra-establishment deliveries, thus included neither in intermediate flows nor in gross production.

It is then important to understand how contracting-out does actually affect such data. This turns out to be strictly dependent on how contracted-out services were in fact provided in the manufacturing firm before outsourcing.

\footnotetext{
${ }^{5}$ In a series of articles published in the late ' 80 s, Postner dealt with the so-called establishment/firm problem and the choice of the statistical unit for the analysis of contractingout in services (e.g. Postner, 1990).
} 
Assuming constant returns to scale and no efficiency gains or losses stemming from outsourcing: ${ }^{6}$

(a) if the service, before outsourcing, is provided by an establishment of the firm itself, whose main activity is the supply of such service (case 1), service outsourcing (case 4) will not change anything;

(b) if the service is supplied by an establishment of the firm, but this provision is only the secondary activity of the establishment, which is instead mainly intended for the production of commodities (case 2), service outsourcing will change both $q_{s}$ and $q_{m}$. The former will increase, because of the increase in $w_{s m}$, while the latter will decrease by the same amount, because of the decrease in $w_{m m}$. At an aggregate level, neither the total gross production nor the total intermediate consumption will change;

(c) if the service, before outsourcing, is produced and consumed within the same accounting period within the same establishment (case 3), outsourcing will make $w_{s m}$ and $q_{s}$ increase, while $q_{m}$ will not change. ${ }^{7}$ Accordingly, both the total gross production and the total intermediate consumption will increase. ${ }^{8}$

These are the effects outsourcing can produce on input-output data by changing establishment classification or the set of goods and services counted as products. However, outsourcing can affect such data also because it can in fact change the valuation of these products. Properly taking into account such effects, in case (a) there will be probably an increase in $w_{s m}$ and in case (b) the increase of $w_{s m}$ will be greater than the decrease of $w_{m m}$, thus increasing the total gross output.

Indeed, one should distinguish between the case in which the establishment produces for the market, and that in which, although the service provision is the primary activity of the establishment, its production is just for

\footnotetext{
${ }^{6}$ In the following discussion the key point is the effect outsourcing produces in inputoutput data by changing the economic unit supplying the service. These effects are not dependent on the changes outsourcing can produce by increasing factor productivity. The latter does not alter the former, and the final result is obtained by summing up the two. Accordingly, in order to better analyze these effects a general ceteris paribus assumption will be made.

${ }^{7}$ If intermediate manufactured goods are needed to supply the service, there will be a decrease in $w_{m m}$ that will be exactly counterbalanced by the increase of $w_{m s}$.

${ }^{8}$ This effect comes simply from the increase of duplication in intermediate consumption, that are strictly dependent on vertical integration degree at establishment level. Thus, for instance, if all manufacturing firms suddenly became one big establishment, $w_{m m}$ would become null and $q_{m}$ would decrease accordingly.
} 
intermediate uses of the firm it belongs to. While in the former case output can be easily valued at market or equivalent market prices, in the latter the establishment is, following the definition of the SNA93, an own-account producer. Although own-account production should be valued at market prices, where this is not feasible, output is in fact treated as non-market and thus valued at production costs. E.g., according to SNA93, both own-account research \& development and own-account software development are measured at production costs (see United Nations, 2006). Contracting-out these activities implies substituting a valuation at production costs with an estimate at market prices, and the latter is usually greater than the former.

\section{What is wrong with Dietrich's approach and what it measures}

As said in Section 2, Dietrich claims that, keeping final demand and technology constant, service outsourcing of manufacturing firms entails a relative change in gross output from manufacturing to services and it is therefore associated with negative values of $Q S$ in Equation (3) for manufacturing. This is so because for Dietrich "each element in a use matrix identifies a production process including intermediate activities for in-house use which are, by definition, not outputs sold to other users and not bought from other suppliers" (1999, pp.223-224).

However, in the above argument there are two flaws. First, the statistical unit in input-output data is not the firm, but the establishment: an establishment mainly providing services is classified in the service sector, no matter which is the firm it belongs to. Second, input-output data do not catch intermediate activities for in-house use: activities which are "not outputs sold to other users" (establishments) "and not bought from other suppliers" (establishments) are just intra-establishment deliveries, not recorded in input-output data. Producer services in particular, where provided within firm boundaries for own consumption, following the terms of SNA93, are mainly ancillary activities, that is, supporting activities undertaken within a firm in order to create the conditions within which the principal or secondary activities can be carried out (United Nations, 2006). As explicitly recognized in the SNA93:

"In practice, the recording of the production of services for own consumption is less common than for goods. Most of the services produced for own consumption by an enterprise (e.g., transportation, storage, maintenance, etc.) are produced by ancillary ac- 
tivities and are thus not separately identified or recorded either under the output or the intermediate consumption of the establishment or the enterprise to which it belongs" (United Nations, 2006, par.6.87).

Thus, even when such services entail transactions between different establishments of a firm, it is not always possible to separately identify and record them under the output and the intermediate consumption.

From what is said above, it follows that there is just one case in which service outsourcing of manufacturing firms brings forth a decrease in the manufacturing gross output and a correspondent increase in the service gross output, namely, the case (b) of the previous section. However, it can be retained just as a "residual" situation. Notably, in the great majority of cases either the service provision is an ancillary activity and thus not recorded as such in input-output data, or it is a primary activity.

Thus, following Dietrich's example of a cleaning service outsourcing made by a manufacturing firm, it seems reasonable to assume that, before outsourcing, the firm, or each of its establishments whether it is a multiplant firm, cleans its storerooms with its own workers, purchasing only goods needed for the purpose, such as brooms and cleansing agents. After the contracting-out, assuming no efficiency gains or losses, input-output data in our simple two industry economy (Equation (4)) will change as follows:

- $w_{s m}$ will increase by the value of contracted-out services, and so will do $q_{s}$;

- $w_{m m}$ will decrease by the value of intermediate manufactured goods needed for service provision, while $w_{m s}$ will increase by the same amount; hence, $q_{m}$ will not change. ${ }^{9}$

- the total gross production $(Q)$ will increase, because of the increase in the total intermediate consumption;

- there will be a decrease in the manufacturing value added and a correspondent increase in that of services. Therefore, the total value added will remain unaltered.

Dietrich emphasizes the meaning of "use" and "make" matrices. As he says:

\footnotetext{
${ }^{9}$ If no input but labour were needed to produce contracted-out activities, neither $w_{m m}$ nor $w_{s m}$ would change. On the contrary, if inputs produced by manufacturing firms are needed to produce services, it holds true that, as stated by Dietrich, outsourcing will make $w_{m m}$ decrease and $w_{s m}$ increase, but, at the same time, it will make also $w_{m s}$ increase, such that, assuming no efficiency gains and constant returns to scale, $q_{m}$ will not decrease.
} 
Explicit consideration must be given to the links between the industry level input-output framework and firm level changes. The industries defined in an I-O system have a characteristic meaning, with each element in the "use" matrix (W) being identified by its inputs, a particular process of production and its outputs. The columns represent activities defined in terms of a product classification. The rows of matrix $\mathbf{W}$ are defined in terms of the inputs into a particular product group. These definitions differ from a "make" matrix that allocates a firm to an industry according to its main activity, including secondary activities. The key point is that these primary and secondary activities are identified in terms of recognisable outputs based on those that are sold, i.e. the value of output from any firm. For a diversified firm, different outputs (with a "make" matrix) can be allocated to different product groups (with a "use" matrix) [...] But each element in a "use" matrix is still defined in terms of output transfers to other producers or final demand and inputs from other firms or primary activities. It follows that each element in a "use" matrix identifies a production process including intermediate activities for in-house use which are, by definition, not outputs sold to other users and not bought from other suppliers (Dietrich, 1999, pp.223-224).

However, Dietrich's argument does not seem conclusive. Here are the flaws already stressed: input-output data do not consider firms, but establishments; intra-establishment deliveries are not counted. "Use" and "make" matrices are built in trying to solve problems posed by joint production (at establishment level) as well as those faced whenever there are more produced goods than industries. But, on the one side, in order to have joint production, service provision has to be a secondary activity; on the other side, industries are aggregation of establishments, not firms.

Hence, what usually makes $q_{m}$ decrease are just efficiency gains stemming from outsourcing: establishments classified in services should use manufacturing inputs to produce services better than establishments classified in manufacturing actually do. However, it is the same as assuming that outsourcing always increases productivity and this is not what Dietrich seems to believe. Thus, while outsourcing can increase sectoral intermediate consumption and total gross output (case c), it does not usually produce any reduction of $q_{m}$, at least when there are no efficiency gains stemming from it.

If outsourcing does not usually bring forth any reduction of $q_{m}$, what is 
then the economic meaning we should give to negative values of $Q S$ in Dietrich's decomposition? To answer this question let us rewrite $Q S$ in Equation (3) as follows:

$$
Q S=\mathbf{L}_{t} \overline{\mathbf{y}}-\mathbf{L}_{t-1} \overline{\mathbf{y}}
$$

where $\overline{\mathbf{y}}=0.5\left(\mathbf{y}_{t-1}+\mathbf{y}_{t}\right)$ is the average final demand. The element $i$ of $Q S$ is then equal to:

$$
Q S_{i}=\sum_{j}{ }_{t} \alpha_{i j} \bar{y}_{j}-\sum_{j}{ }_{t-1} \alpha_{i j} \bar{y}_{j}
$$

where ${ }_{t} \alpha_{i j}$ and $\bar{y}_{j}$ are the generic elements of, respectively, $\mathbf{L}_{t}$ and $\overline{\mathbf{y}}$. Recalling that ${ }_{t} \alpha_{i j}$ represents the value of $i$ needed, directly and indirectly, to produce a unit value of $j$ in a certain period $t$ (see, for instance, Pasinetti, 1979), the first summation gives the value of $i$ needed to produce the average final demand $\overline{\mathbf{y}}$ in $t$, whereas the second summation works out this value for the period $t-1$. Accordingly, $Q S_{i}$ can be thought of as the reduction in direct and indirect input requirements of $i$ needed to produce $\overline{\mathbf{y}}$ between $t-1$ and $t$. When constant prices data are used, all the previous measures can be viewed as physical quantities and $Q S_{i}$ becomes the saving in physical input requirements of $i$ occurred between $t-1$ and $t$, keeping final demand constant.

This is exactly what McCarthy \& Anagnostou (2004) do. As said in Section 3, they apply Dietrich's decomposition to UK yearly input-output tables at constant prices and work out $Q D$ and $Q S$ for manufacturing. Therefore, they estimate just the savings of manufacturing input requirements, but these savings are due only to productivity increases and not to organizational restructuring, at least until the latter does not cause the former. They claim that service outsourcing always entails a reduction in manufacturing gross output and that this reduction can be measured by Dietrich's decomposition, but I proved that there is no gross output reduction usually associated with outsourcing and what $Q S$ measures are just efficiency gains.

However, although service outsourcing does not make manufacturing gross output decrease, as said before, it can increase total gross output. So, the share of manufacturing on the total gross output could decrease, whereas the service share could increase. ${ }^{10}$ As said before, to get rid of the inflation problem, rather than comparing absolute values using constant prices as done by McCarthy \& Anagnostou (2004), Dietrich calculates the manufacturing gross output and the sectoral final demand as a proportion of the total output to decompose the changes of the manufacturing share in the total gross output (see Equation (5)).

\footnotetext{
${ }^{10}$ E.g., in our simple example service outsourcing can make $q_{s}$ increase, keeping $q_{m}$ unaltered. Accordingly, the ratio $q_{m} /\left(q_{m}+q_{s}\right)$ would become smaller and $q_{s} /\left(q_{m}+q_{s}\right)$ larger.
} 
Besides the problems already stressed, here is another one. According to Dietrich, the first summation of Equation (5) should give the changes in the manufacturing output induced by the changes in the final demand, but, when the latter is expressed as a proportion of the total gross output, it does not hold true anymore. As a matter of fact, keeping the final demand vector $(\mathbf{y})$ constant, $Q D^{*}$ is negative whenever $Q_{t}>Q_{t-1}$, but this is exactly what could happen every time there is outsourcing!

It is worth noting this is the same error McCarthy \& Anagnostou (2004) make when, after having worked out $Q S$ for manufacturing using inputoutput tables at constant prices, they calculate the manufacturing share that would have been in the non-outsourcing case and compare it with the actual share, in order to appraise the underestimation of manufacturing (see note 4). In so doing, they implicitly assume that the total output of the economy is never affected by outsourcing, an assumption which has finally proved faulty.

\section{Conclusive remarks}

Although mainly investigated as a process of organizational change, of the firm boundaries in particular, outsourcing has important implications also for the structure of the economic system in which the outsourcee and the outsourcer firms operate. What might be termed the "structural implications" of outsourcing come from two different sources. First, outsourcing tends to strengthen horizontal linkages, thus contributing to create intersectoral networks of productive relations. Second, outsourcing widens market boundaries, enlarging the set of goods and services exchanged through market transactions.

Economists have recently tried to measure the effect that this reorganization of production has had on economic structure, and especially on the shares of manufacturing and services. In particular, using Dietrich's (1999) decomposition approach, McCarthy \& Anagnostou (2004) analyze the impact of service contracting-out in the UK manufacturing decline over the '80s and '90s.

However, as proved in the present paper, the decomposition suggested by Dietrich (1999) has got some evident flaws and it does not measure what they claim it does. Indeed, this method does not properly take into account how input-output tables actually record economic phenomena. Thus, it is undoubtedly true that "outsourcing is a management process that alters the boundary of an organization and therefore changes the economic contribution that an organization makes to its industrial sector and thus to the economy" (McCarthy \& Anagnostou, 2004, p.64). However, one should carefully ana- 
lyze how national accounts, input-output tables in particular, are built and what they record, because the way in which data are recorded and collected turns out to be crucial for assessing the exact impact economic phenomena have on them.

In order to show the flaws of Dietrich's method, this paper has carefully analyzed the linkages between service outsourcing and input-output data. Thus, it might prove useful also in avoiding further mistakes in using input-output analysis for studying outsourcing-related changes in economic structure.

\section{References}

Dietrich, M. (1999) Explaining economic restructuring: an input-output analysis of organisational change in the European Union, International Review of Applied Economics, 13(2), pp. 219-240.

McCarthy, I. \& Anagnostou, A. (2004) The impact of outsourcing on the transaction costs and boundaries of manufacturing, International Journal of Production Economics, 88, pp. 61-71.

Pasinetti, L. L. (1979) Lectures on the Theory of Production (London: Palgrave Macmillan).

Postner, H. H. (1990) The contracting-out problem in service sector analysis: Choice of statistical unit, Review of Income and Wealth, 36(2), pp. 177186.

United Nations (1999) Handbook of input-output table compilation and analysis, Studies in Methods Series F, No.74, UN Statistics Division, New York.

United Nations (2006) System of national accounts 1993, Studies in Methods Series F, No.2, United Nations Statistics Division, New York, http:// unstats. un.org/unsd/sna1993/. 